\title{
Selected topical medications: Patterns, knowledge and preference in clinical practice among Nigerian physiotherapists
}

\author{
Onigbinde Ayodele Teslim ${ }^{1}$, Olatipe Christianah Folake ${ }^{1}$, Tarimo Nesto ${ }^{2}$, Mukoka Grace ${ }^{3}$ \\ ${ }^{1}$ Department of Medical Rehabilitation, College of Health Sciences, Obafemi Awolowo University, Ile-Ife, Osun State, Nigeria \\ ${ }^{2}$ Department of Physiotherapy, Malawi Against Physical disabilities, P. O. Box 256, Blantyre, Malawi \\ ${ }^{3}$ Department of Physiotherapy, College of Medicine, University of Malawi, Blantyre, Malawi
}

\section{Email address:}

ayotesonigbinde@yahoo.co.uk (A. T. Onigbinde)

\section{To cite this article:}

Onigbinde Ayodele Teslim, Olatipe Christianah Folake, Tarimo Nesto, Mukoka Grace. Selected Topical Medications: Patterns, Knowledge and Preference in Clinical Practice among Nigerian Physiotherapists. American Journal of Health Research. Special Issue: Supplementary Prescribing in Nigeria: A Needy Concept to Promote Clinical Physiotherapy Practice. Vol. 2, No. 5-1, 2014, pp. 22-28. doi: $10.11648 /$ j.ajhr.s.2014020501.15

\begin{abstract}
Application of topical medication remains an essential component of clinical physiotherapy practice but previous reports have revealed poor knowledge of medications among Nigerian physiotherapists. Also, there are arrays of topical medications available but there is envelope of doubts on what determines the choice of Nigerian physiotherapists. The primary aims of this study were to investigate the pattern and preference of selected topical medications in clinical practice among physiotherapists. A structured self administered questionnaire was administered to 200 physiotherapists in purposively selected hospitals in Southwest, Nigeria. Descriptive statistics of mean, standard deviation and percentages were used to analyze the data. The results showed that most physiotherapists were familiar with diclofenac sodium (92.0\%) and methyl salicilate (92.5\%) while very few were familiar with dexamethasone, zinc oxide ,magnesium sulphate, capsaicin and naproxen $(27.0 \%, 34.5 \%$, $35.0 \%, 36.0 \%$ and $37.0 \%$ ) respectively. The results also showed that $56.5 \%$ and $63.5 \%$ of physiotherapists were correct about functions of diclofenac sodium and glucosamine sulphate respectively. Only $8 \%, 20.5 \%$ and $2.5 \%$ physiotherapists knew the functions of magnesium sulphate as an analgesic and as a muscle relaxant; and lidocaine as an anesthetic agent. The results further revealed that $34.0 \%$ and $17.0 \%$ chose menthol and dexamethasone respectively as their least preferred topical medications and they based their choice mostly on efficacy, active ingredients in the drugs and reported efficacy by patients. Most physiotherapists (63.3\%) were not correct about the dominant ions present in the selected topical medications. We concluded that physiotherapists in this study were mostly familiar with diclofenac sodium and methyl salicylate but diclofenac was the most preferred topical medication in clinical practice. There was general poor knowledge on functions and dominant ionic charges in the topical medications.
\end{abstract}

Keywords: Topical Medications, Physiotherapy, Preference, Knowledge, Efficacy

\section{Introduction}

There are several topical medications but of utmost importance to physiotherapists are analgesics, Non-steroidal anti-inflammatory drugs (NSAIDs) and muscle relaxants [1]. Topical analgesics have been observed to provide effective analgesia with reduced systemic drug levels [2]. Topical application of NSAIDs had been reported to provide bioavailability and plasma concentrations of between $5 \%$ and $15 \%$ when compared to those which are delivered through the systemic [3].
There is a paradigm shift towards utilizing a local effect in pain management especially for common neuropathic and musculoskeletal conditions [4]. Considering the potential adverse end-organ effects, the American College of Geriatrics cautioned the use of oral NSAIDS and COX-2 inhibitors among geriatrics; topical analgesics was recommended as an option [5]. Topical analgesics are in different formulations which include: creams, drops, foam, gel, ointment, plaster or patches and sprays [6]. The active ingredients in most are Benzocaine, Camphor, Capsaicin, Diphenhydramine, Hydrocortisone, Lidocaine, Menthol, 
Methyl salicylate, Pramoxine, and Trolamine salicilate [7].

There are still uncertainties in appropriateness and dosage specification for topical NSAIDs [1], [8]. Effort had been made to provide quantification for topical cream and gel using Finger Tip Unit (FTU). Finlay et al and Long and Finlay defined FTU as the amount of ointment, cream or other semi-solid dosage form expressed from a tube with a $5 \mathrm{~mm}$ diameter nozzle, applied from the distal skin crease to the tip of the index finger of an adult as a determinant for dose of topical medications and one FTU has been reported to be equivalent to $0.5 \mathrm{mg}$ [9], [10].

Topical rubefacient produces counterirritant effects by irritating pattern of sensory activity that diminishes pain intensity; it also reduces local blood flow. Salicylates act via these mechanisms and are used for arthritic and rheumatic pain [11]. Analgesics and non-steroidal anti-inflammatory drugs (NSAIDs) are the most common pharmaceuticals for alleviating the pain and reduced function of musculoskeletal conditions [12].

There appears to be indiscriminate use of both analgesics and NSIADS among Nigerian physiotherapists. It appears they based prescription on which of topical NSAIDS or analgesics is readily available. Also, there is dearth of data on the most preferred in terms of efficacy and usefulness in physiotherapy practice. Furthermore, physiotherapists utilize iontophoresis in patient's management and this requires appropriate knowledge of ionic charges in topical medications. The aims of this study are to investigate the prescription pattern of topical medications, and determine the most preferred topical medication among Nigerian physiotherapists.

\section{Materials and Methods}

\subsection{Study Settings}

The study settings are 5 Teaching hospitals, 2 State hospitals and 2 Private hospitals. Others are 1 Private clinic, 2 Physiotherapy training schools, 1 Federal medical centre and 1 National orthopaedic hospital in southwest, Nigeria.

\subsection{Research Design}

This study was a cross sectional exploratory survey design. The respondents provided the required information at the specific arranged period [13].

\subsection{Sampling Technique}

They were sample of convenience from 14 purposively selected health institutions.

\subsection{Sample}

The sample comprised 200 practicing physiotherapists (110 males and 90 females). The major inclusive criteria were that the respondent must have the current practicing license, and must be fully employed at the time of the study. The participants must be willing to participate; and also willing to complete the questionnaire at arranged time and returned it immediately. Physiotherapists who were not licensed or unwilling to participate in the study were excluded.

\subsection{Instrument}

A self administered questionnaire was used for this study. It was a modification of the questionnaire used by Onigbinde et al [14]. The modification was the inclusion of familiarity and drug preference in tabulated form into the original questionnaire. To allow for respondents differing educational backgrounds, the questions were kept as simple as possible. The questionnaire was divided into 4 sections namely:

A. Demographics and academic related data:

This comprises eight questions that required demographic information and academic related data from the participants such as gender, age, work setting, update on knowledge etc

B. Patterns and Knowledge of Topical analgesics and NSAIDS:

This consists of nine-columned questions assessing physiotherapists' knowledge, familiarity and effects of the listed drugs namely:

Piroxicam (feldene gel), diclofenac sodium (voltaren gel), methyl Salicylate (Neurogesic), menthol, ketoprofen (ketonal gel), Ibuprofen (ibrucap gel), lidocaine gel, naproxen, zinc oxide paste, glucosamine Sulphate (urah cream), magnesium sulphate gel, capsaicin and dexamethasone cream.

C. Preference Ratings of Selected Topical Analgesics and NSAIDS:

This section consists of questions on the preferred ratings of physiotherapists on these selected drugs in terms of clinical efficacy. It was divided into three categories: the most preferred, preferred and least preferred options respectively. Also, this section inquires reasons for the preferring chosen options.

D. Knowledge of Dominant Ion of Selected Topical Analgesics and NSAIDS:

This section consists of questions on knowledge of dominants ion of the topical medications.

Prior to the main study, a draft of the modified questionnaire was pilot tested. Five physiotherapists from Obafemi Awolowo University, who were not part of the main study, were implored to assess the new questionnaire. They examined the questionnaire for simplicity, viability and precision. They also ensured that the questionnaire reflects the underlying concept and objectives of the study [15]. Changes were made based on their responses and the revised questionnaire was used for the main study

\subsection{Procedure}

The ethics and Research committee of Institute of Public Health Obafemi Awolowo University Ile-Ife, Osun State, Nigeria granted approval for the study (IPH/OAU/12/159). Permission was also granted by the heads of physiotherapy department at each work setting.

The aims of the study were explained to each participant 
and they were assured of confidentiality of information given while consent form was also signed them. In other to maintain anonymity; participants' names were not required on the questionnaire. The questionnaire was completed within the participant's convenient time as there was no time limit specification. The questionnaire was completed in presence of the main investigator in order to avoid cheating and interaction with colleagues as this may affect outcome of individual knowledge.

The questionnaire were collated and entered into SPSS, version 17 in a private and password protected computer which only members of the research team have access to. Responses were obtained from two hundred and twenty (220) physiotherapists in total, out of two hundred seventy (270) copies of questionnaire that were distributed. Thirty respondents refused to submit copies of their questionnaires after completion, and no specific reason was given for their action. We assumed that it might be due to very poor knowledge of listed medications. Thus, there was a response rate of $81.5 \%$. But only 200 were analyzed, representing an overall response rate of $74.10 \%$ as twenty (20) copies of the questionnaire were invalidated due to inconsistencies and failure to comply with essential instructions.

\subsection{Data Management}

Descriptive statistics of mean, standard deviation, frequency and percentages were used to analyse the data. Data analysis was carried out using statistical package for social sciences software version 17 .

\section{Results}

Table 1. Demographic profile and academic related data

\begin{tabular}{|c|c|c|c|}
\hline Variables & & $\begin{array}{l}\text { Frequency } \\
\mathbf{n}=\mathbf{2 0 0}\end{array}$ & Percentage \\
\hline \multirow{4}{*}{ Age (years): } & $22-27$ & 48 & 24.0 \\
\hline & $28-33$ & 59 & 29.5 \\
\hline & $34-39$ & 46 & 23.0 \\
\hline & 40 and above & 47 & 23.5 \\
\hline \multirow{3}{*}{$\begin{array}{l}\text { Highest } \\
\text { Qualification: }\end{array}$} & Bachelors degree & 145 & 72.5 \\
\hline & Masters degree & 43 & 21.5 \\
\hline & Doctorate degree & 12 & 6.0 \\
\hline \multirow{5}{*}{ Experience: } & $1-5$ years & 84 & 42.0 \\
\hline & $6-10$ years & 50 & 25.0 \\
\hline & $11-15$ years & 29 & 14.0 \\
\hline & $15-20$ years & 24 & 12.0 \\
\hline & $\begin{array}{l}\text { Greater than } 20 \\
\text { years }\end{array}$ & 13 & 6.5 \\
\hline \multirow{5}{*}{ Work Settings: } & Private Hospital & 16 & 8.0 \\
\hline & State Hospital & 37 & 18.5 \\
\hline & Teaching Hospital & 106 & 53.0 \\
\hline & Academics & 6 & 3.0 \\
\hline & Others & 35 & 17.5 \\
\hline \multirow{2}{*}{$\begin{array}{l}\text { Seeking for } \\
\text { knowledge: }\end{array}$} & Yes & 108 & 54.5 \\
\hline & No & 90 & 45.5 \\
\hline
\end{tabular}

One hundred and ten $(55 \%)$ respondents were male while ninety (45\%) were female; and one hundred and six respondents $(53.0 \%)$ were working at teaching hospitals. The age, range, highest qualification and years of experience are represented in Table 1. Seventy-three respondents (35.7\%) recently updated their knowledge on topical medications and ninety respondents $(45.0 \%)$ sought educational information. The frequency of knowledge update is also presented in table 1. Most respondents relied on seminar presentations by drug companies to update their knowledge. The professional body (Nigeria Society of Physiotherapy) and the regulatory organ in Nigeria (Medical Rehabilitation Registration Board) were the least source of gaining knowledge (Figure 1).

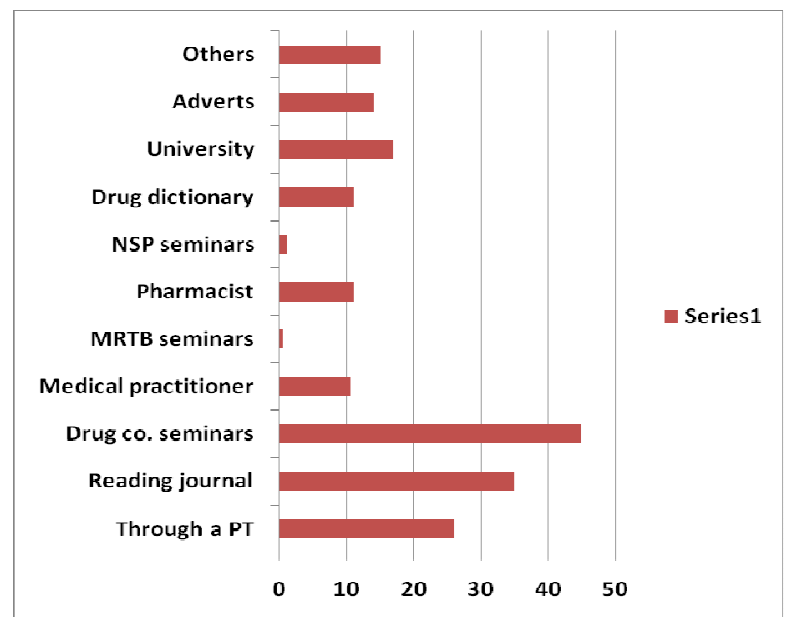

Figure 1. Sources of updating topical medication knowledge. Key: MRTBMedical rehabilitation therapy board. NSP - Nigerian Society of Physiotherapy, Drug co. - Drug companies

\subsection{Familiarity and Knowledge with Selected Topical Medications}

One hundred and eighty four (92.0\%), 185 (92.5\%), 70 (35\%), 54 (27\%) respondents were familiar with diclofenac sodium, methyl salicilate, magnesium sulphate and zinc oxide respectively. Only few physiotherapists were familiar with zinc oxide, dexamethasone, magnesium oxide, capsaicin and naproxen. The frequency of respondents' familiarity to listed drugs is presented in figure 2. Only 95 (47.5\%) and 113 (56.5\%) respondents could correctly identify piroxicam, and diclofenac sodium as NSAIDs, however, 127 (63.5\%) respondents were correct about the effect of glucosamine sulphate on cartilage synthesis (Table 2).

Furthermore, only $16(8 \%)$ and $41(20.5 \%)$ respondents were correct about the roles of Magnesium sulphate as an analgesic and a muscle relaxant respectively. The frequency distribution and percentages of other drugs are summarized in the Table 2. Preference for selected topical medications

One hundred and thirteen (113) respondents (56.5\%) chose diclofenac sodium as the most preferred topical medications. Also, 89 (44.5\%), 81 (40.5) respondents chose glucosamine sulphate and methyl salicylate respectively as the most preferred drugs. For the least preferred option, 68 respondents (34.0\%) chose menthol, 34 respondents (17.0\%) chose dexamethasone while 32 respondents $(16 \%)$ chose capsaicin. The summary of preferences is presented in Table 3. 
Table 2. Frequency distribution of respondent's knowledge about functions/roles of selected drugs

\begin{tabular}{|c|c|c|c|c|c|c|}
\hline \multirow{2}{*}{ Drugs } & \multicolumn{2}{|c|}{ NSAIDs } & \multicolumn{2}{|c|}{ Analgesics } & \multicolumn{2}{|c|}{ Other effects } \\
\hline & $\mathbf{F}$ & $\%$ & $\mathbf{F}$ & $\%$ & $\mathbf{F}$ & $\%$ \\
\hline Piroxicam & 95 & 47.5 & 73 & 36.5 & - & - \\
\hline Diclofenac & 113 & 56.5 & 95 & 47.5 & - & - \\
\hline Salicylate & 64 & 32.0 & 130 & 65.0 & - & - \\
\hline Menthol & - & - & 101 & 50.5 & - & - \\
\hline Ketoprofen & 65 & 31.5 & 50 & 25.0 & - & - \\
\hline Ibuprofen & 105 & 52.5 & 98 & 49.0 & 5 & 2.5 \\
\hline Lidocaine & - & - & 70 & 35.5 & - & - \\
\hline Naproxen & 35 & 17.5 & 38 & 19.0 & - & - \\
\hline Zinc oxide & - & - & - & - & 20 & 10 \\
\hline $\begin{array}{l}\text { Glucosamine } \\
\text { sulphate }\end{array}$ & - & - & 30 & 15.0 & 127 & 63.5 \\
\hline Magnesium & - & - & 16 & 8.0 & 41 & 20.5 \\
\hline Capsaicin & - & - & 41 & 20.5 & - & - \\
\hline Dexamethasone & 28 & 14.0 & - & - & - & - \\
\hline
\end{tabular}

Keys: F - Frequency

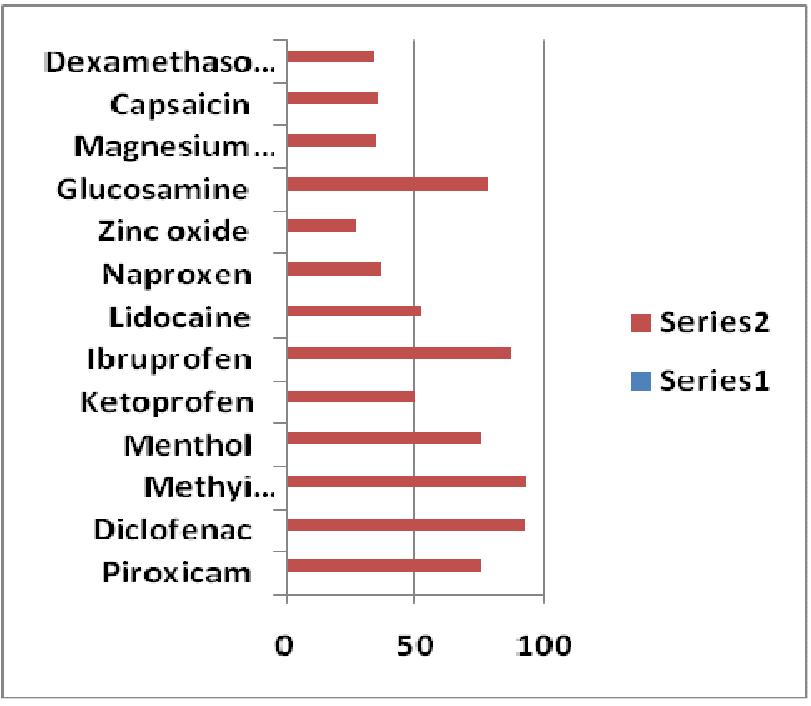

Figure 2. Respondent's familiarity

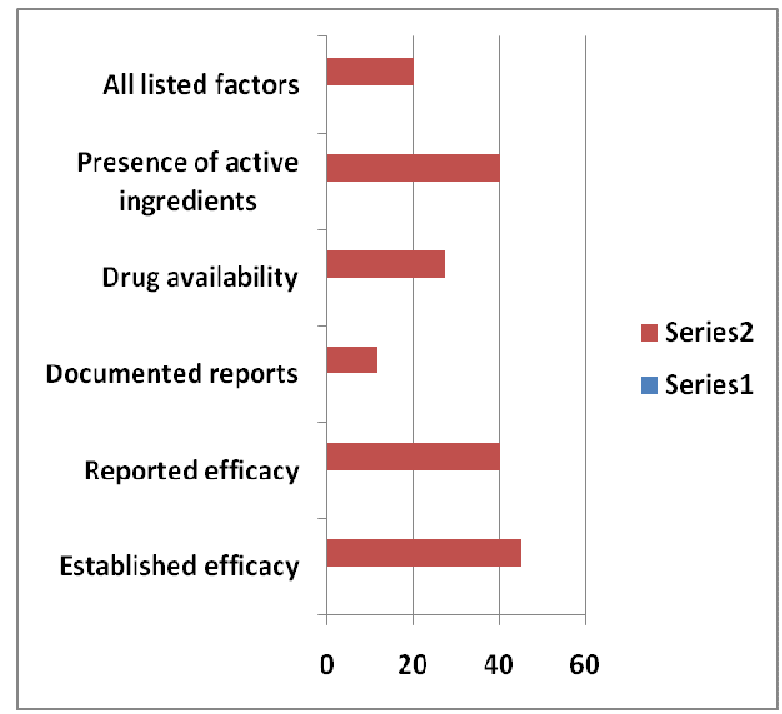

Figure 3. Reasons for preference
Table 3. Frequency distribution of Preference of selected topical medications in terms of efficacy in clinical practice (Multiple Choice Questions)

\begin{tabular}{lllllll}
\hline \multirow{2}{*}{ Medications } & \multicolumn{2}{l}{$\begin{array}{l}\text { Most } \\
\text { Preferred }\end{array}$} & \multicolumn{2}{l}{ Preferred } & \multicolumn{2}{l}{$\begin{array}{l}\text { Least } \\
\text { Preferred }\end{array}$} \\
\cline { 2 - 7 } & F & \% & F & \% & F & \% \\
\hline Piroxicam & 44 & 22.0 & 79 & 39.5 & 11 & 5.5 \\
Diclofenac & 113 & 56.5 & 52 & 26.5 & 2 & 1.0 \\
Methyl Salicylate & 81 & 40,5 & 76 & 38.0 & 23 & 11.5 \\
Menthol & 20 & 10.0 & 58 & 29.0 & 68 & 34.0 \\
Ketoprofen & 7 & 3.5 & 51 & 25.5 & 29 & 14.5 \\
Dexamethasone & 4 & 2.0 & 35 & 17.5 & 34 & 17.0 \\
Ibruprofen & 48 & 24.0 & 79 & 39.5 & 19 & 9.5 \\
Zinc Oxide & 5 & 2.5 & 25 & 12.5 & 28 & 14.0 \\
Lidocaine & 13 & 6.5 & 42 & 21.0 & 27 & 13.5 \\
Naproxen & 9 & 4.5 & 36 & 18.0 & 20 & 10.0 \\
Glucosamine & 89 & 44.5 & 38 & 19.0 & 10 & 5.0 \\
Magnesium sulph & 7 & 3.5 & 29 & 14.5 & 29 & 14.5 \\
Capsaicin & 2 & 1.0 & 38 & 19.0 & 32 & 16.0 \\
\hline
\end{tabular}

Keys: F frequency

On the question on what their preferences is (are) based on in relation to its efficacy in clinical practice, 90 respondents $(45 \%)$ based their preference on known efficacy while 80 respondents $(40 \%)$ based it on reported efficacy by patients and 23 respondents $(11.5 \%)$ based it on documented reports. The frequency distribution and percentages of reasons for preference are represented in Figure 3.

\subsection{Knowledge of the Dominant Ions Presents in the Selected Topical Drugs}

Most respondents were unable to provide answers to the questions that were asked on dominants ion available in the topical formulations of the medications. Only few respondents were able to answer out of which a larger percentage of the respondents were incorrect. The results of knowledge of ions of the selected drugs are represented in Table 4.

Table 4. Frequency distribution on knowledge of selected topical medications

\begin{tabular}{lllll}
\hline \multirow{2}{*}{ Medications } & \multicolumn{2}{l}{ Positive (+ ve) } & \multicolumn{2}{l}{ Negative (- ve) } \\
\cline { 2 - 5 } & F & \% & F & \% \\
\hline Piroxican & 50 & 25.0 & 15 & $7.5^{*}$ \\
Diclofenac & 77 & 38.5 & 16 & $8.0^{*}$ \\
Salicylate & 52 & 26.5 & 30 & $15.0^{*}$ \\
Menthol & 33 & 6.5 & 32 & 16.0 \\
Ketoprofen & 35 & 17.5 & 20 & $10.0^{*}$ \\
Ibuprofen & 47 & 23.5 & 22 & $11.0^{*}$ \\
Lidocaine gel & 27 & $13.5^{*}$ & 29 & 14.5 \\
Naproxen & 25 & 12.5 & 19 & $9.5^{*}$ \\
Glucosamine sulphate & 45 & $22.5^{*}$ & 34 & 17.0 \\
Zinc oxide & 38 & $19.0^{*}$ & 26 & 13.0 \\
Capsaicin & 18 & 9.0 & 26 & $13.0^{*}$ \\
Magnesium Sulphate & 44 & 22.0 & 25 & $12.5^{*}$ \\
Dexamethasone & 23 & 11.5 & 19 & $9.5^{*}$ \\
\hline
\end{tabular}

*Frequency of respondents who gave correct answers

\section{Discussion}

Pain management requires inter and multidisciplinary approaches (Algiatry) in order to alleviate and improve the 
quality of life of those living with pain ([16], [17], [18]. Persistent acute and unrelieved pain results to chronic pain which subsequently leads to anatomical and genetic changes in the nervous system [19]. Previous reports favoured NSAIDs as the commonest drugs used in the management of pain [12] [20] Topical anaesthetics and analgesics have physiological effects on the peripheral nerves and soft tissue underneath site of application and it is now evidence based in clinical practice that they are as effective as those administered through oral route [21], [22]. Transdermal application of NSAIDs and analgesic techniques using massage, iontophoresis and phonophoresis remains key tools for the management of pain. Although, transdermal massage and phonophoresis are easily applied with appropriate skills, iontophoresis requires an in-depth knowledge of bio-active ingredients/ionic charges of drugs.

Almost half of the respondents did not show keen interest in seeking educational knowledge of topical medications while few updated their knowledge in relevant pharmacology areas. This contradicted the reports of Onigbinde et al where most physiotherapists showed interest in improving their pharmacology knowledge, although, this previous study investigated physiotherapist's opinion on becoming supplementary prescribers of oral and inject-able drugs and this might have stimulated their interest [1]. Amongst those that had quest for gaining knowledge, most respondents attended seminar presentations organized by drug companies, read journals and interacted with colleagues in order to improve their knowledge of topical medications. The professional body (NSP), the registration board of Nigeria (MRTRB) and training institutions which are recognised organs to train and organize continuing education programme might have been redundant as only very few respondents chose them as source of acquiring knowledge.

Majority of the respondents were familiar with diclofenac sodium, methyl salicylate and glucosamine sulphate but diclofenac was the most preferred topical medication being used in clinical practice. In a recent study by Onigbinde et al; patients with musculoskeletal dysfunctions also reported that oral diclofenac was the most prescribed NSAID among health professionals; hence, this is corroborating the importance of both oral and topical diclofenac in clinical practice, probably due to its efficacy [23].

The respondents were familiar with menthol, contrarily; it was among the least preferred medications. There is similarity in frequencies of respondents on non-familiarity and least preference for capsaicin, zinc oxide, dexamethasone, lidocaine, naproxen; and magnesium sulphate despite their importance in clinical physiotherapy practice. There are reports buttressing the relevance of these least preferred topical medications in practice. Capsaicin $(0.025 \%-0.25 \%$ concentration) and menthol are major ingredients in most topical analgesics [24] [25]. Capsaicin plays key role in the management of pain associated with diabetic neuropathy, osteoarthritis and psoriasis [26]. Combination of capsaicin cream $(0.075 \%)$ and lidocaine iontophoresis had been reported to be effective in alleviating pain in a diabetic patient with neuropathy [27]. Similarly, Onigbinde et al reported that lidocaine iontophoresis decreased the pain intensity experienced by patients during application of mobilization techniques while Baskurt et al and reported that iontophoresis and phonophoresis of naproxen are equally effective in the treatment of lateral epicondylitis [28] [29] [30].

Amongst the medications that respondents have less familiarity and least preference in clinical practice are magnesium sulphate which has analgesic and relaxant properties; zinc oxide that has vasodilatory and anti-septic effects; and dexamethasone with anti-inflammatory effect especially in the procedure of iontophoresis [1], [31], [32]. Similarly, menthol has analgesic properties which are mediated through a selective activation of k-opioid receptors and blocking of voltage-sensitive sodium channels, reducing neural activity that may stimulate muscles [33], [34]. We attributed poor familiarity and non-preference for these topical medications to lack of quest for further knowledge among the physiotherapists.

Less than half of the physiotherapists were able to identify Piroxicam as an NSAID despite the familiarity, while only $2.5 \%$ of respondents could identify lidocaine as an anaesthetic agent. These are in line with reports of Kumar and Grimmer's who reported poor knowledge of drugs among Australian physiotherapists [35]. However, majority of the respondents were correct about function of glucosamine sulphate as enhancing cartilage synthesis. Reports have favoured glucosamine's ability to facilitate the production of cartilage and enhancing joint functions [3], [37]. There was rationale choice of topical medications among the physiotherapists as most respondents favoured efficacy in clinical practice, presence of active ingredients in the drugs a6nd reported efficacy by patients as reasons for their preferences while few respondents based their preferences on drug availability at the department and documented reports.

Most respondents showed poor knowledge of dominant ion in topical formulations of these drugs despite the claim that they recently update their knowledge, and this finding has been similar trends in most previous studies [1], [8], [14]. This finding implied that Nigerian physiotherapists have not been making concerted efforts to improve their knowledge of pharmacology because previous studies were conducted in almost the same clinical settings. Adequate knowledge of dominant ions in drugs are vital for the process of iontophoresis and medical technology is re-focusing towards increasing interest in enhancement of drug penetration through iontophoresis [14].

We concluded that physiotherapists were most familiar with diclofenac sodium, methyl salicylate and glucosamine sulphate but diclofenac was the most preferred topical medication in clinical practice. Only few physiotherapists have adequate knowledge about functions of most of these drugs despites their familiarities with them. There was general poor knowledge of dominant ionic charges in the listed drugs. We recommend training programmes on 
relevant aspects of pharmacotherapy that will enhance clinical practice for Nigerian physiotherapists.

\section{References}

[1] Onigbinde AT, Bamitale KDS, Olaogun MOB, Makinde OO, Adetoogun GE, Odeyemi E. (2013). Opinion and knowledge of Nigerian physiotherapists on relevance and usefulness of pharmacology education on dosage of topical medications: International journal of pharmacy and pharmacology Vol.2 (1)

[2] Zelzter Lonnie (2004). The Use of Topical Analgesics in the Treatment of Neuropathic Pain: Mechanism of Action, Clinical Efficacy, and Psychologic Correlates; available at http://www.medscape.org/neurology

[3] Heyneman CA, Lawless-Liday C, Wall GC. (2000): Oral versus topical NSAI-Ds in rheumatic diseases: a comparison. Drugs, 60:555-574.

[4] Woolf CJ, Salter MW. (2000). Neuronal plasticity: increasing the gain in pain. Science. 288(5472):1765-1769.

[5] Mannion RJ, Woolf CJ. (2000). Pain mechanisms and management: a central perspective. Clin J Pain. 16(3):S144S156.

[6] Stanos Steven DO, (2009). In Overview of topical analgesics; Pain Medicine News Special Topical pain relievers, 2010).

[7] Topical pain relievers (2010). What Over-the-Counter Analgesics Are. CHPA Educational Foundation. http://otcsafety.org/en/treatments/topical-pain-relievers/. Accessed on $17^{\text {th }}$ june 2014.

[8] Kumar S and Grimmer K (2005). Non-Steroidal Anti inflammatory Drugs (NSAIDs), and Physiotherapy Management of Musculoskeletal Conditions: a professional minefield? Centre for Allied Health Evidence, Australia. J. Clin. Risk Manag. 1 (1): 69-76.

[9] Finlay AY, Edwards PH, Harding KG (1989). Finger tip unit in dermatology. Lancet, II: 155.

[10] Long CC, Finlay AY (1991). The fingertip unit: a new practical measure. Clin. Exper.Dermatol. 16: 444-446.

[11] Dworkin (2007). Cited by Jana Sawynok in Topical analgesics; CPS pain Education Day (2010). pain 132:237.

[12] Moore RA, Tramer MR, Carroll D, Wiffen PJ and McQuay HJ (1998). Quantitative systematic review of topically applied non-steroidal anti-inflammatory drugs. British MedicalJournal 316:333-338.

[13] Mathers Nigel, Nick Fox,Amanda Hunn (2009) Surveys and Questionnaires. The NIHR Research Design Service for Yorkshire \& the Humber. www.rds-eastmidlands.nihr.ac.uk

[14] Onigbinde AT, Olaogun MOB, Irogue K (2012). An evaluation of the knowledge level of Nigerian Physiotherapists on topical pharmacotherapy Hong Kong PhysiotherapyJournal.Vol. 1 Pgs $1-7$

[15] García de Yébenes Prous M. Jesús, a, F Francisco Rodríguez Salvanés, b and Loreto Carmona Ortells (2009). Validation of questionnaires. Reumatol Clin. 2009;5 (4):171-177.

[16] Hardy, Paul AJ. (1997): Chronic pain management: the essentials. U.K.: Greenwich MedicalMedia.

[17] Main, Chris J; Spanswick, Chris C. (2000). Pain management: an interdisciplinary approach. Churchill Livingstone.

[18] Thienhaus Ole, Cole B. Eliot (2002). "The classification of pain". In Weiner, Richard S,. Pain management: A practical guide for clinicians. CRC Press. p. 29

[19] Rajapopal MR. (2006): Pain-basic considerations: Indian J. Anaesth. 50(5): 331-334.

[20] National Health Research (2014). Treatment for knee pain. Knee pain Spotlightweb.pdf. Accessed march 12, 2014.

[21] Galer BS (2001). Topical medications. In: Loeser JD, ed, Bonica's Management of pain. Philadelphia: LippincottWilliams \& Wilkins; 1736-1741.

[22] McCleane G (2007). Topical analgesics. Anesthesiol Clin. 25:825-839

[23] Onigbinde Ayodele Teslim, M'Kumbuzi Vyvienne, Olaogun Mathew Olatokunbo, Afolabi Joshua Oluwafisayo etal (2014). Side effects of Non-Steroidal Anti-Inflammatory Drugs: The experience of patients with musculoskeletal disorders. Submitted for publication in America journ of Health Research.

[24] Tramer MR (2004). "It's not just about rubbing--topical capsaicin and topical salicylates may be useful as adjuvants to conventional pain treatment". BMJ328 (7446): 998.

[25] Topical capsaicin for pain relief, 2007 Bandolier. www.medicine.ox.ac.uk/bandolier/. Accessed on $4^{\text {th }}$ June 2014

[26] McQuay HJ, Moore RA (1998). Topical capsaicin. An evidenced -based resource for pain relief.Oxford. Oxford university press, in Topical capsaicin for pain relief, 2007 Bandolier. www.medicine.ox.ac.uk/bandolier/. Accessed on 4th June 2014.

[27] Ogata K, Masaki T, Kunimoto M, Inoue K (1996). Therapeutic trials with topical capsaicin cream and iontophoretically applied lidocaine for diabetic painful tuncal neuropathy, Rinsho Shinkeigaku (1): $30-33$.

[28] Onigbinde AT, Talabi AE, Ogunsakin EA, Adesoye AA, Awotipe A Mbada CE, Obiyemi OO, Oyerinde O (2010). Acute effect of lidocaine iontophoresis on pain and joint motions during application of mobilization techniques- A Technical Report. Ghana Journal ofPhysiotherapy Vol 2 No 1, $23-29$.

[29] Başkurt F, Ozcan A, Algun C (2003). Comparison of effects of phonophoresis and iontophoresis of naproxen in the treatment of lateral epicondylitis. Clin Rehabil. Feb;17(1):96-100.

[30] Ganvir Shyam D (2012). Efficacy of phonophoresis and iontophoresis of naproxen in the treatment of lateral epicondylitis. Journal of Pharmaceutical and Scientific Innovation, JPSI 1 (4), July, 65 - 66.

[31] Browning JD, Reeves PG, O’Dell BL (1987). Zinc deficiency in rat reduces the vasodilation response to bradykinin and prostacclin. Journal of nutrition, 117, (3): $490-5$.

[32] Marovino Tiziano and Graves Claire (2008). Iontophoresis in pain management. Practical pain management.www.practicalpainmanagent .com/Treatment/ interventional/ ionto -phoresis -painmanagement. 8: (2).Accessed on $4^{\text {th }}$ June 2014 
[33] Haeseler D, Maue J, Grosskreutz J, Bufler B, Nentwig S, Piepenbrock R, Dengler and M. Leuwer. (2002). "Voltagedependent block of neuronal and skeletal muscle sodium channels by thymol and menthol". European Journal of Anaesthesiology 19 (8): 571-579.

[34] Galeottia N, Mannellia LDC, Mazzantib G, Bartolinia A, Ghelardini C (2002). "Menthol: a natural analgesic compound".Neuroscience Letters 322 (3): 145-148.

[35] Kumar S, Grimmer K (2005). Non-Steroidal AntiInflammatory Drugs (NSAIDs), and Physiotherapy
Management of Musculoskeletal Conditions: a professional minefield? Centre for Allied Health Evidence, Australia. J. Clin. Risk Manag. 1 (1): 69-76.

[36] The Glucosamine osteoarthrirtis resource centre (2005). Glucosamine and osteoarthritis,http://www.glucosamineosteoarthritis.org/glucosamine/Gluosamine .html; [Accessed 13.03.13].

[37] Braham R, Dawson B, Goodman C. (2003). The effect of glucosamine supplementation on people experiencing regular knee pain. Br J Sports Med;37:45-9. 